ISSN: 0377-6395
e-ISSN: 2651-4214

doi: $10.33188 /$ vetheder. 482840

Araştırma Makalesi / Research Article

\title{
Beta hidroksi bütirik asit düzeyinin diğer metabolik test parametreleri üzerine etkisi
}

\author{
Ramazan YILDIZ ${ }^{a *}$, Merve IDER ${ }^{b}$, Mahmut $\mathrm{OK}^{b}$ \\ ${ }^{a}$ Mehmet Akif Ersoy Üniversitesi, Veteriner Fakültesi, İ̧̧ Hastalıklarl Anabilim Dall, 15030, Burdur, Türkiye \\ ${ }^{b}$ Selçuk Üniversitesi, Veteriner Fakültesi, İç Hastalıkları Anabilim Dalı, 42031, Konya, Türkiye
}

\begin{abstract}
MAKALE BILGISI:
ARTICLE INFORMATION:

Geliş / Received:

14 Kasim 18

14 November 18

Kabul / Accepted:

11 Aralık 18

11 December 18

Anahtar Sözcükler:

Metabolik profil,

beta hidroksi butirik asit,

sığgr
\end{abstract}

Keywords:

Metabolic profile,

beta-hydroxybutyrate, cattle
ÖZET:

Metabolik profil test, süt sı ğırlarının metabolik durumlarını ortaya koymak ve metabolizma hastalıklarının erken tanısına yardımcı olmak amacıyla yapılan bir testtir. Bu çalışmada, negatif enerji dengesizliği olan sütçü sı̆̆ırların metabolik profil test parametrelerindeki değişimlerin ve bu parametreler arasındaki ilişkilerin ortaya konulması amaçlandı. Çalışma, laktasyon döneminin ikinci haftasında olan 189 adet sı̆̆ır serum örneğinin metabolik profil test sonuçları retrospektif olarak değerlendirilerek yapıldı. Kan beta hidroksi butirik asit (BHBA) seviyesi 1 mmol/L'nin üstünde olan hayvanlar Grup-1'e, 1 mmol/L'den düşük olan hayvanlar ise Grup-2'ye dahil edildi. BHBA düzeyi keton ölçüm cihazı ile yapıldı. Glikoz, kan üre azotu (BUN), magnezyum (Mg), aspartat aminotransferaz (AST), fosfor (P), kolesterol, total protein, albümin, kalsiyum, gama glutamil transferaz (GGT) analizleri otoanalizör ile yapıldı. Grup-1'in glikoz ( $p<0,001)$ ve albümin ( $p<0,01)$ düzeylerinin Grup-2'den anlamlı derecede düșük, GGT $(p<0,001)$, AST (p<0,05) ve kalsiyum $(\mathrm{p}<0,01)$ düzeylerinin ise Grup-2'den anlamlı derecede yüksek olduğu tespit edildi. BHBA düzeyinin glikoz $(\mathrm{p}<0,01)$ ile negatif, AST $(\mathrm{p}<0,01)$ ve GGT $(\mathrm{p}<0,01)$ ile pozitif korelasyon gösterdiği belirlendi. Sonuç olarak BHBA değeri $1 \mathrm{mmol} / \mathrm{L}$ ve üzerine çıktığı durumlarda karaciğer ile ilişkili hasarı gösteren enzimlerin de artmaya başladığı gözlendi. Subklinik ketozis tespit edilen sürülerde negatif enerji dengesinin ortadan kaldırılmasının yanında karaciğer destekleyici tedavilerin verilmesi ve sürünün karaciğer yağlanma riski için kontrol edilmesinin de önemli olduğu kanısına varıldı.

\section{The effect of beta-hydroxybutyrate level on other metabolic test parameters}

\section{ABSTRACT:}

Metabolic profile test was performed to determine the metabolic status of dairy cattle and to use in the early diagnosis of metabolic diseases. The aim of this study was to determine the changes in metabolic profile test parameters of dairy cattle with negative energy balances and the relationships between these parameters. The metabolic profile results of 189 cattle within the first 2 wk of lactation period were evaluated retrospectively. Animals with a Beta-hydroxybutyrate (BHBA) threshold level above $1 \mathrm{mmol} / \mathrm{L}$ were assigned to Group-1 and the animals with blood BHBA levels less than 1 $\mathrm{mmol} / \mathrm{L}$ to Group-2. BHBA level was assessed by blood ketone meter. Glucose, blood urea nitrogen (BUN), magnesium (Mg), aspartate aminotransferase (AST), phosphorus (P), cholesterol, total protein, albumin, calcium and gamma glutamyl transferase (GGT) analyzes were performed by the auto-analyzer. Group-1 levels of glucose $(p<0.001)$ and albumin ( $\mathrm{p}<0.01)$ were found to be significantly lower, GGT $(\mathrm{p}<0.001)$, AST ( $<<0.05)$, and calcium ( $\mathrm{p}<0.01)$ were significantly higher than Group-2. BHBA level was found to be negatively correlated with glucose $(\mathrm{p}<0.01)$ and with a positive correlation with AST $(\mathrm{p}<0.01)$ and GGT $(\mathrm{p}<0.01)$. In conclusion, the enzymes showing liver damage started to increase when BHBA value was above $1 \mathrm{mmol} / \mathrm{L}$. In addition to the treatment of the negative energy balance in the cattle with subclinical ketosis, it was concluded that supportive therapies for the liver should be performed and check the risk of the fatty liver in herd.

\footnotetext{
* Sorumlu yazar / Corresponding author eposta adresi/e-mail address: ramazanyildiz@ mehmetakif.edu.tr
} 


\section{Giriş}

Metabolik profil test, süt sığırlarının metabolik durumlarını ortaya koymak ve metabolizma hastalıklarının erken tanısına yardımcı olmak amaciyla yapılan bir testtir (19). Metabolik profil test, sürü tabanlı tanı amaciyla kullanılan spesifik analitik testlerin kombinasyonu olarak tanımlanmaktadır (34). Süt sığırlarında metabolik profildeki değişim, genellikle gebeliğin 7. ayından itibaren başlar ve laktasyonun ilk dönemini içerisine alır. Bu dönemde uygun bakım ve besleme ile metabolik hastalıklar kontrol altına alınıp verim artışı sağlanabilir. Beslenme veya beslenmeyle ilişkili hastalıkların tanısı, sürü sağlığı açısından oldukça önemlidir (4).

Süt sığırcılığı işletmelerinde periparturient hastalıklar; kesime sevkler, ölümler, süt veriminde azalmalar, reprodüktif problemler ve veteriner hizmetlerine yapılan harcamalar ile yetiştiriciler için ciddi ekonomik kayıplara neden olmaktadır (9). Süt ineklerinde hastalıkların \%80'i periparturient dönemde ortaya çıkmaktadır. Bunun temelini de metabolizma bozuklukları oluşturmaktadır. Süt ineklerinin, laktasyonun ilk 2 ayı içerisinde daha sık hastalıklara yakalandıkları net bir şekilde ortaya konulmuştur. Süt ineklerinde enerji metabolizması bozuklukları (ketozis, subklinik ketozis ve yağlı karaciğer sendromu) ve mineral metabolizması yetersizliklerinin (doğum felci, subklinik hipokalsemi) periparturient dönemde immun sistemi zayıflatarak mastitis, retensiyo sekundinarum, endometritis, uterus involusyonunda gecikme ve tırnak hastalıklarının ortaya çıkışını kolaylaştırdı̆̆ı belirlenmiştir $(5,14,33)$. Japonya Hokkaido'da 1997 yılı istatistiklerine göre 550.000 periparturient dönem sütçü sığırın 65.000'inin (yaklaşık \%12) hipokalsemi, karaciğer yağlanması, abomasum deplasmanları, ketozis, yatalak inek sendromu ve retensiyo sekundinarum gibi periparturient hastalıklar nedeniyle veteriner hekimler tarafindan tedavi edildiği, bu sütçü sığırlardan 8.000'inin ise tedaviye cevap vermediği için kesime sevk edildiği belirlenmiştir (20).

Negatif enerji dengesi (NED) şiddeti ve süresinin doğru tahmin edilmesi; sürü yönetimi, besleme stratejileri ve döl verimi için gereklidir (29). Enerji dengesi; hayvan sağlı̆̆ını, laktasyon ve üreme performansını etkileyen önemli bir faktördür (34). Enerji dengesi; hayvanın yemlerle aldığı enerjiden, harcadığı enerjinin fark1 olarak tanımlanmaktadır (21). Yemlerle alınan enerji, yaşama ve verim payları için yeterli olmalıdır. Eğer rasyonla yeterli enerji alınamazsa, negatif enerji dengesi meydana gelmektedir. Bu durum ketozis, yağlı karaciğer sendromu gibi metabolik hastalıkların oluşumuna zemin hazırlamaktadır. Negatif enerji dengesinin önceden belirlenmesi ve gerekli tedbirlerin alınması üretim performansının tutturulması, karlılığın devamı ve sürü sağlığı açısından önemlidir $(21,28)$. Macrae ve ark (22) yaptıkları bir çalışmada enerji dengesinin belirlenmesinde beta hidroksi butirik asit (BHBA), glikoz ve esterleşmemiş yağ asidi (NEFA) parametrelerini kullanmışlardır. BHBA, özellikle doğumdan sonra laktasyonun 5. ile 50. günleri arasında subklinik ketozisin belirlenebilmesinde önem taşımaktadır $(6,19)$. Serum BHBA seviyesi laktasyondaki sığırlarda $1 \mathrm{mmol} / \mathrm{L}$ altında, kurudaki sığırlarda $0,6 \mathrm{mmol} / \mathrm{L}$ 'nin altında olmalıdır. Serum BHBA seviyesi 1,4 mmol/L'den fazla olduğu zaman klinik ketozis gelişme ihtimali oldukça artmaktadır $(19,26)$.

$\mathrm{Bu}$ çalışmada, negatif enerji dengesi olan sütçü sığırların metabolik profil test parametrelerindeki değişimlerin ortaya konulması ve bu parametreler arasındaki ilişkilerin belirlenmesi amaçlandı.

\section{Gereç ve Yöntem}

Yapılan çalışmada, Selçuk Üniversitesi Veteriner Fakültesi Merkez Klinik Laboratuvarına metabolik profil test analizi için getirilen sığır kan örneklerinin geçmiş yılların metabolik profil test verileri analiz edilmiş ve laktasyon döneminin ikinci haftasında olan farklı 9 çiftlikten 189 adet sığıra ait metabolik profil test sonucu retrospektif olarak incelenmiştir. Belirtilen laktasyon dönemindeki 189 adet sütçü sığıra ait verilerde kan beta hidroksi butirik asit (BHBA) seviyesi $1 \mathrm{mmol} / \mathrm{L}$ 'nin üstünde olan hayvanlar Grup-1'e (n=37), $1 \mathrm{mmol} / \mathrm{L}$ 'den düşük olan hayvanlar ise Grup-2'ye (n=152) dahil edildi. Yapılan metabolik profil testinde BHBA düzeyi ölçümü için keton ölçüm cihazı (Precision Xtra, Abbott Diabetes Care, Abingdon, UK) kullanıldı. Diğer metabolik profil test analizleri [Glikoz, kan üre azotu (BUN), magnezyum (Mg), aspartat aminotransferaz (AST), fosfor (P), kolesterol, total protein, 
albümin, kalsiyum ve gama glutamil transferaz (GGT)] için ise otoanalizer (BT 3000 plus, Instrumention Laboratory Company, Milan, Italy) cihazı kullanıldı.

\section{İstatistiksel analiz}

Araştırmada elde edilen verilerin Kolmogorov-Smirnov testi kullanılarak normal dağılımı belirlendi. Gruplar arası farklılıkları belirlemek için bağımsız student's $t$-testi kullanıldı. BHBA ve diğer metabolik test parametreleri (Glikoz, BUN, Mg, AST, P, kolesterol, total protein, albümin, kalsiyum, GGT) arasındaki ilişkiyi belirlemek için Pearson's korelasyon testi kullanıldı. İstatistiksel analizler için SPSS programı (versiyon 22.0) (Chicago, SPSS Inc.) kullanıldı. $\mathrm{p}<0,05$ değeri istatistiki açıdan önem sınırı kabul edildi.

\section{Bulgular}

Gruplara ait BHBA, glikoz, BUN, Mg, AST, P, kolesterol, total protein, albümin, kalsiyum ve GGT değerleri Tablo 1'de verildi. Grup-1'in glikoz $(p<0,001)$ ve albümin $(p<0,01)$ düzeylerinin Grup-2'den anlamlı derecede düşük, GGT $(p<0,001)$, AST $(p<0,05)$ ve kalsiyum $(p<0,01)$ düzeylerinin ise Grup-2'den anlamlı derecede yüksek olduğu tespit edildi. İki grup arasında BUN, $\mathrm{P}, \mathrm{Mg}$, total protein ve kolesterol ortalamaları arasında istatistiksel farklılık olmadığı gözlendi (Tablo 1). BHBA düzeyinin glikoz $(\mathrm{p}<0,01)$ ile negatif yönlü, AST $(\mathrm{p}<0,01)$ ve GGT $(p<0,01)$ ile pozitif yönlü bir korelasyonu tespit edilirken diğer parametreler ile korelasyon belirlenmedi (Tablo 2).

Tablo 1: Gruplar arası metabolik profil parametrelerindeki değişimler (mean $\pm \mathrm{SEM}$ ).

Table 1: Changes in metabolic profile parameters between groups (mean \pm SEM).

\begin{tabular}{cccc}
\hline $\begin{array}{c}\text { Parametreler } \\
(\text { Mean } \pm \text { SEM) }\end{array}$ & Grup 1 $(\mathbf{n = 3 7})$ & Grup 2 (n=152) & P değeri \\
\hline GLU (mg/dL) & $40.4 \pm 2.66$ & $55.8 \pm 0.93$ & $<0.001$ \\
BUN (mg/dL) & $11.5 \pm 0.63$ & $10.7 \pm 0.25$ & 0.256 \\
MG (mg/dL) & $2.48 \pm 0.04$ & $2.49 \pm 0.03$ & 0.816 \\
AST (U/L) & $110.9 \pm 9.25$ & $91.0 \pm 1.89$ & 0.042 \\
P (mg/dL) & $6.80 \pm 0.21$ & $6.73 \pm 0.32$ & 0.853 \\
CHOL (mg/dL) & $164.1 \pm 11.3$ & $156.1 \pm 3.73$ & 0.509 \\
PRO (g/dL) & $8.07 \pm 0.12$ & $8.10 \pm 0.09$ & 0.838 \\
ALB (g/dL) & $3.46 \pm 0.05$ & $3.61 \pm 0.02$ & 0.017 \\
Ca (mg/dL) & $10.1 \pm 0.17$ & $9.62 \pm 0.09$ & 0.010 \\
GGT (U/L) & $34.9 \pm 3.42$ & $22.4 \pm 0.60$ & $\leq 0.001$ \\
BHBA (mmol/L) & $1.50 \pm 0.13$ & $0.44 \pm 0.01$ & $<0.001$ \\
\hline
\end{tabular}

GLU, Glikoz; BUN, Kan Üre Azotu; MG, Magnezyum; AST, Aspartat Aminotransferaz; P, Fosfor; CHOL, Kolesterol; PRO, Total Protein; ALB, Albumin; Ca, kalsiyum; GGT, Gama Glutamil Transferaz; BHBA, Beta-hidroksi büturik asit

Tablo 2: BHBA ve diğer metabolik profil test parametreleri arasında korelasyon (mean \pm SEM).

Table 2: Correlation between BHBA and other metabolic profile test parameters (mean \pm SEM).

\begin{tabular}{ccccccccccc}
\hline Parametreler & GLU & BUN & MG & AST & P & CHOL & PRO & ALB & Ca & GGT \\
\hline BHBA & $-.304^{* *}$ & -.054 & -.091 & $.421^{* *}$ & .048 & -.043 & -.047 & -.142 & .032 & $.457^{* *}$
\end{tabular}

GLU, Glikoz; BUN, Kan Üre Azotu; MG, Magnezyum; AST, Aspartat Aminotransferaz; P, Fosfors; CHOL, Kolesterol; PRO, Total protein; ALB, Albumin; Ca, Kalsiyum; GGT, Gama Glutamil Transferaz; BHBA, Beta-hidroksi büturik asit; **,Correlation is significant at the 0.01 level (2-tailed) 


\section{Tartışma ve Sonuç}

Geçiş dönemi periyodunda, inekler normal olarak NED'e girerler. NED adipoz dokudan karaciğere NEFA formunda lipid mobilizasyonu ile karakterizedir. Süt üretimi için gerekli olan enerjiyi karşılamak üzere NEFA enerji kaynağı olarak kullanılmaktadır (7). Ketozis genellikle karaciğere aşırı NEFA infiltrasyonu ile ilişkilidir. Karaciğer kapasitesini aşan aşırı NEFA akışı karaciğerin NEFA'yı tamamen oksidize etme yeteneğini bozmakta ve bu durum kısmen oksitlenmiş NEFA'nın ürünü olan BHBA, asetoasetat ve aseton gibi keton cisimlerinin artışına sebep olmaktadır. BHBA dolaşımdaki dominant keton cismidir ve tüm vücutta, plazmada veya serumda nispeten stabil olarak bulunmaktadır $(10,11,15,25)$. Ketozisin tanısı kan BHBA düzeyine dayanmaktadır (2). Süt ineklerinde ketozisin tanısı için farklı BHBA eşik değerleri kullanılmaktadır (12,18,25). BHBA konsantrasyonun 1.0 mmol/L'nin üzerinde olması subklinik ketozis, $2.6 \mathrm{mmol} / \mathrm{L}$ üzerinde olması klinik ketozis olarak değerlendirilmektedir. Bireysel bazda klinik bulguların tam olarak hangi düzeyde görüleceği oldukça değişkendir (3). Nazifi ve ark (24) yaptıkları çalışmada subklinik ketozis eşiğini BHBA > $1.0 \mathrm{mmol} / \mathrm{L}$ olarak belirlemiş̧lerdir. Walsh ve ark (35) laktasyonun ilk haftasında $1 \mathrm{mmol} / \mathrm{L}$ 'den ve ikinci haftasında ise $1.4 \mathrm{mmol} / \mathrm{L}$ 'den yüksek BHBA düzeylerinin reprodüktif performansı azalttığını bildirmişlerdir. Benzer şekilde Ospina ve ark (25), laktasyonun ilk iki haftasında BHBA seviyeleri $1.0 \mathrm{mmol} / \mathrm{L}$ 'den yüksek olan ineklerin abomasum deplasmanı ve metritise yakalanma olasılıklarının sırasıyla 6.9 ve 2.3 kat daha fazla olduğunu bildirmişlerdir. Yapılan bu çalışmada hayvan gruplandırma kriterleri kan BHBA seviyelerine dayandığından, gruplar arasında BHBA düzeyleri önemli düzeyde farklıydı $(\mathrm{p}<0.001)$. Bu retrospektif analizde ortalama olarak, birinci grupta bulunan laktasyondaki ineklerde belirlenen BHBA düzeyi $(1,50 \pm 0,13)$ subklinik ketozis için belirlenen eşik değerin $(1.4 \mathrm{mmol} / \mathrm{L})$ üzerinde kalmıştır. Bu durum, sürülerdeki ineklerin çoğunluğunun subklinik ketozise (30 adet sığır) ve bazılarının ise klinik ketozise (5 adet sığır) maruz kaldığını göstermektedir. Süt sığırlarında yüksek kan NEFA ve BHBA seviyeleri negatif enerji balansının temel göstergeleridir. Bir sürünün ketozis, karaciğer yağlanması ve NED durumunu değerlendirmek için metabolik profil testinde NEFA, BHBA, glikoz, albümin, GGT ve BUN düzeylerinin dikkate alınması gerektiği bildirilmiştir (2). Çalışma gruplarımız arasında Grup-1'in glikoz $(\mathrm{p}<0,001)$ ve albümin $(\mathrm{p}<0,01)$ düzeylerinin Grup-2'den anlamlı derecede düşük, GGT $(p<0,001)$, AST $(p<0,05)$ ve kalsiyum $(p<0,01)$ düzeylerinin ise anlamlı derecede yüksek olduğu tespit edildi (Tablo 1). Diğer metabolik parametreler (BUN, fosfor, magnezyum, total protein ve kolesterol) arasında istatistiksel farklılık bulunmadı (Tablo 1). BHBA ile yalnızca glikoz, AST ve GGT arasında anlamlı $(\mathrm{p}<0,01)$ korelasyon tespit edildi (Tablo 2). Karaciğere yă̆ infiltasyonu, hepatik dokuda hasara sebep olmakta ve buna bağlı olarak karaciğer hasarını gösteren AST, GGT ve glutamat dehidrogenaz (GLDH) gibi enzimlerin seviyeleri genellikle artmaktadır (5,15). Ruminantlarda lipomobilizasyonun kandaki temel indikatörü BHBA ve NEFA'dır. Hepatik lezyon ve fonksiyonunun temel indikatörü ise enzim olarak AST, GGT ve GLDH iken metabolit olarak glikoz, kolesterol ve albümindir (37). Ketozis ve karaciğer yağlanması yakın şekilde ilişkili olup, sütçü işletmelerde süt veriminin düşmesine ve sürüden çıkarılan hayvan oranın artmasına bağlı olarak ciddi ekonomik kayıplara sebep olmaktadır (15). Ropstad ve ark (27) kronik ketozis vakalarında şiddetli karaciğer yağlanmasının meydana gelebileceğini bildirmişlerdir. Karaciğer ve safra kanalı işlev bozukluklarında GGT'nin serum konsantrasyonu artış gösterirken (31) AST seviyesindeki artış karaciğerdeki yağ birikimine bağlı hepatosit permeabilitesindeki artışın yansımasıdır. Grummer (16) ve Stojević ve ark (32) süt sığırlarında yüksek AST konsantrasyonlarının yağlı karaciğer sendromu, düşük kuru madde alımı ve ketozis bulguları ile ilişkili olduğunu bildirmişlerdir. Ayrıca laktasyon başındaki ineklerde AST konsantrasyonunun metabolik karaciğer hastalıklarının saptanmasında GGT'den daha üstün olduğu bildirilmiştir (15,31). Akgül ve ark (2) kan GGT düzeyinin hepatik lipidozis ile pozitif korelasyon gösterdiğini bildirmiştir. Bu çalışmada Grup 1' deki sı̆̆ırların serum GGT (p<0,001) ve AST $(\mathrm{p}<0,05)$ konsantrasyonunun istatistiksel olarak yüksek olduğu tespit edildi. BHBA düzeyi yüksek olan Grup-1' deki serum AST ve GGT aktivitelerinin önemli oranda artması karaciğer fonksiyon bozukluğunun bir göstergesi olabilir (31). Gonzalez ve ark (15) ketozisli ineklerde hepatositlerde biriken yă asitlerinin karaciğerin 
fonksiyonunu bozduğunu ve yağ birikimine bağlı hepatik değişiklikler nedeniyle albümin sentezinin azalabileceğini belirtmişlerdir. Karaciğerde yağ infiltrasyonu, bazı kan bileşenlerinin konsantrasyonunu da etkileyebilir. Glikoz seviyelerinin yanı sira total protein, albümin ve üre konsantrasyonları da azalabilmektedir (36). Glikoz, protein, albümin ve BUN seviyeleri hepatik işlevsellik göstergeleri olup $(5,15,36)$ konsantrasyonlarında azalmalar yüksek lipomobilizasyona sahip hayvanlarda yă̆ infiltrasyonunu yansitabilmektedir (17,30). Mevcut çalışmada Grup-1'in albümin $(\mathrm{p}<0,01)$ düzeyinin anlamlı düzeyde düşük olduğu belirlendi. Yapılan çalışmada belirlenen düşük albümin seviyeleri daha önce yapılan çalışmalarda belirtildiği gibi $(13,30)$ hepatik fonksiyon bozukluğu ile ilişkili olabileceği düşünülmektedir. Yapılan çalışmada Grup-1'in glikoz $(\mathrm{p}<0,001)$ düzeyinin anlamlı düzeyde düşük ve BHBA düzeyi ile kan glikoz düzeyleri arasında negatif korelasyon olduğu belirlendi. Ketozisli ineklerde yapılan çalışmalarda BHBA düzeyinin yüksek ve glikoz düzeyinin ise düşük olduğu bildirilmiştir $(1,8,23,38)$. Postpartum laktasyon periyodu sırasında glikoz alımı ve meme bezinde glikoz kullanımı arasındaki dengesizlik sonucu hipoglisemi meydana gelebilmektedir. Kandaki düşük glikoz düzeyine cevap olarak yağ mobilizasyonu başlatılır. Glikoz yokluğu sonucu meydana gelen enerji kaybını telafi etmek için NEFA oksidasyonu ve BHBA üretimi artmaktadır (11). Bu bulguların yapılan diğer çalışmalar $(1,8,23,38)$ ile uyumlu olduğu görüldü.

Ketozis ve kalsiyum metabolizması arasında birbirini doğrudan etkileyen bir ilişki mevcuttur. Genel olarak, ketozisli hayvanlarda değişen derecelerde hipokalsemi şekillenmektedir. Ketozisde değişik derecelerde metabolik asidoz nedeniyle iyonize kalsiyum genellikle normal olmasına rağmen, total kalsiyum konsantrasyonunda bir azalma gelişebilmektedir. Başoğlu ve Sevinç (4) asidozisin proteinlere (özellikle albümin) kompleks halde bağli bulunan kalsiyumun ayrılmasını artırdığını ve kemiklerdeki kalsiyumun daha kolay mobilize olmasını sağlayarak dolaşımdaki kalsiyum miktarının artabileceğini bildirmiştir. Sunulan çalışmada kalsiyum seviyeleri normal düzeylerde olmasına rağmen Grup-1'de Grup-2'den daha yüksek bulunmuştur. Subklinik ketozis gibi süt veriminin azalmaya başlayacağ1 durumlarda sütle kaybedilen kalsiyum miktarı da azalacağından, Grup-1'de belirlenen kalsiyum artışının süt veriminin düşüşüyle ilişkili olabileceği düşünülmektedir.

Sonuç olarak BHBA değeri $1 \mathrm{mmol} / \mathrm{L}$ ve üzerine çıktığı durumlarda karaciğer ile ilişkili hasarı gösteren enzimlerin de artmaya başladığı görüldü. Subklinik ketozis tespit edilen sürülerde negatif enerji dengesinin ortadan kaldırılmasının yanı sıra karaciğer destekleyici tedavilerin de yapılmasının önemli olduğu kanısına varılmıştır. Ayrıca bu sürülerde BHBA ile birlikte değişim gösteren AST ve GGT gibi enzimlerde yükselmenin tespit edilmesi halinde karaciğer yağlanması yönünden ultrasonografik muayene ve biyopsi incelemelerinin yapılması gerekliliğinin ortaya çıkacağı düşünülmektedir.

\section{Kaynaklar}

1. Akamatsu H, Saitoh Y, Serizawa M, Miyake K, Ohba Y, Nakashima K (2007): Changes of serum 3methylhistidine concentration and energy-associated metabolites in dairy cows with ketosis. J Vet Med Sci, 69 , 1091-1093.

2. Akgul G, Mecitoglu Z, Kucuksen DU, Senturk S (2018): Comparison of adiponectin levels and some metabolic parameters in dairy cows with subclinical and clinical ketosis. Med Weter, 74(3), 182-186.

3. Andersson L (1984): Concentrations of blood and milk ketone bodies, blood isopropanol and plasma glucose in dairy cows in relation to the degree of hyperketonaemia and clinical signs. Zentralbl Veterinarmed A, 31(1-10), 683-693.

4. Basoglu A, Sevinc M (2004): Metabolik ve Endokrin Hastallklar. Pozitif Press, Ankara.

5. Bobe G, Young JW, Beitz DC (2004): Invited review: pathology, etiology, prevention, and treatment of fatty liver in dairy cows. J Dairy Sci, 87(10), 3105-3124.

6. Butler WR (2000): Nutritional interactions with reproductive performance in dairy cattle. Anim Reprod Sci, 60, 449-457. 
7. Contreras GA, Sordillo LM (2011): Lipid mobilization and inflammatory responses during the transition period of dairy cows. Comp Immunol Microbiol Infect Dis, 34, 281-289.

8. Dann HM, Morin DE, Bollero GA, Muphy MR, Drackley JK (2005): Prepartum intake, postpartum induction of ketosis and preparturient disorders affect the metabolic status of dairy cows. J Dairy Sci, 88, 32493264.

9. Deluyker HA, Gay JM, Weaver LD, Azari AS (1991): Change of milk yield with clinical diseases for a high producing dairy herd. J Dairy Sci, 74(2), 436-445.

10. Dohoo IR, Martin SW (1984): Subclinical ketosis: prevalence and associations with production and disease. Can J Comp Med, 48, 1-5.

11. Dufield T (2000): Subclinical ketosis in lactating dairy cattle. Vet Clin North Am Food Anim Pract, 16, 231253.

12. Eicher R, Liesegang A, Bouchard E, Tremblay A (1998): Influence of concentrate feeding frequency and intrinsic factors on diurnal variations of blood metabolites in dairy cows. Proc Am Assoc Bov Pract, p. 198202.

13. El-Deeb WM, El-Bahr SM (2017): Biochemical markers of ketosis in dairy cows at post-paturient period: oxidative stress biomarkers and lipid profile. Vet Arhiv, 87(4), 431-440.

14. Goff JP, Horst RL (1997): Physiological changes at parturition and their relationship to metabolic disorders. J Dairy Sci, 80(7), 1260-1268.

15. González FD, Muiño R, Pereira V, Campos R, Benedito JL (2011): Relationship among blood indicators of lipomobilization and hepatic function during early lactation in high yielding dairy cows. J Vet Sci, 12(3), 251255.

16. Grummer RR (1993): Etiology of lipid-related metabolic disorders in periparturient dairy cows. J Dairy Sci, 76, 3882-3896.

17. Haass LC, Eness GP (1984): Bovine fatty liver syndrome. Iowa State Veterinarian, 46(2), 108-111.

18. Jorritsma R, Balde ESJC, Schukken YH, Wensing TH, Wentink GH (1998): Evaluation of a milk test for detection of subclincal ketosis. Vet Q, 20, 108-110.

19. Kennerman E (2011): Metabolic profile test in dairy cows. Turkiye Klinikleri J Vet Sci, 2(2):96-101.

20. Kida K (2002): The metabolic profile test: its practicability in assessing feding management and periparturient diseases in high yielding commercial dairy herds. J Vet Med Sci, 64(7), 557-563.

21. Leblanc SJ, Lissemore KD, Kelton DF, Duffield TF, Leslie KE (2006): Major advences in disease prevention in dairy cattle. J Dairy Sci, 89(4), 1267-1279.

22. Macrae AI, Whitaker DA, Burrough E, Dowell A, Kelly JM (2006): Use ofmetabolic profiles for the assessment of dietary adequacy in UK dairy herds. Vet Rec, 159, 655-661.

23. Mecitoglu Z, Senturk S, Akgul G, Udum D, Uzabaci E, Kasap S, Catik S (2016): Changes in circulating adiponectin and tumour necrosis factor- $\alpha$ and their relationship with insulin resistance in periparturient dairy cows. Vet Res, 60, 163-167.

24. Nazifi S, Mohebbi FM, Rowghani E, Behbood MR (2008): Studies on the relationship between sub-clinical ketosis and liver injuries within the first two months of lactation period in high producing Iranian Holstein cows. Int J Dairy Sci, 3(1), 29-35.

25. Ospina PA, Nydam DV, Stokol T, Overton TR (2010): Evaluation of nonesterified fatty acids and $\beta$ hydroxybutyrate in transition dairy cattle in the northeastern United States: Critical thresholds for prediction of clinical diseases. J Dairy Sci, 93(2), 546-554.

26. Quiroz-Rocha GF, LeBlanc SJ, Duffield TF, Wood D, Leslie KE, Jacobs RM (2009): Reference limits for biochemical and hematological analytes of dairy cows one week before and one week after parturition. Can Vet J, 50, 383-388. 
27. Ropstad E, Halse K, Refsdal AO (1999): Variations in parameters of liver function and plasma progesterone related to underfeeding and ketosis in a dairy herd. Acta Vet Scand, 30, 185-197.

28. Rukkwamsuk T, Wensing T, Geelen MJH (1998): Effect of overfeeding during the dry period on regulation of adipose tissue metabolism in dairy cows during the periparturient period. J Dairy Sci, 81, 2904-2911.

29. Serbester U, Cınar M, Hayırlı A (2012): Sütçü ineklerde negatif enerji dengesi ve metabolik indikatörleri. Kafkas Univ Vet Fak Derg, 18(4), 705-711.

30. Sevinç M, Başoğlu A, Güzelbektaş H, Boydak M (2003): Lipid and lipoprotein levels in dairy cows with fatty liver. Turk J Vet Anim Sci, 27(2), 295-299.

31. Steen A, Grønstøl H, Torjesen PA (1997): Glucose and insulin responses to glucagon injection in dairy cows with ketotis and fatty liver. J Vet Med A, 44(1-10), 521-530.

32. Stojević Z, Piršljin J, Milinkovićtur S, Zdelar-tuk M, Ljubić BB (2005): Activities of AST, ALT and GGT in clinically healthy dairy cows during lactation and in the dry period. Vet Arhiv, 75, 67-73.

33. Şahal M, Colakoğlu EC, Alihossenini H (2011): Ketozis ve yağlı karaciğer sendromunun tedavisinde guncel yaklaşımlar ve tedavideki başarısızlığın nedenleri. Turkiye Klinikleri J Vet Sci, 2(2), 140-150.

34. Van Saun RJ (2007): Application of a pooled sample metabolic profile for use as a herd screening tool. Danish Bovine Practitioner Seminar Middelfart, Denmark. p. 24-25.

35. Walsh RBJS, Walton JS, Kelton DF, Leblanc SJ, Leslie KE, Duffield TF (2007): The effect of subclinical ketosis in early lactation on reproductive performance of postpartum dairy cows. J Dairy Sci, 90, 2788-2796.

36. West HJ (1990): Effect on liver function of acetonaemia and the fat cow syndrome in cattle. Res Vet Sci, 48 , 221-227.

37. Wittwer F (1995): Empleo de los perfiles metabólicos en el diagnóstico de desbalances metabólicos nutricionales en el ganado. Buiatría Bovinos, 2, 16-20.

38. Yameogo N, Oudraogo GA, Kanyandek WEC, Sawadako GJ (2008): Relationship between ketosis and dairy cows' blood metabolites in intensive production farms of the periurban area of Dakar. Trop Anim Health Prod, 40, 483-490. 